\title{
Proposta de modelos matemáticos que descrevam o tempo de execução financeira dos projetos de pesquisa apoiados pelo FIPE/HCPA
}

\author{
Cristian Fidalgo Cabral ${ }^{a^{*}}$, Rafael Leal Zimmer ${ }^{\mathrm{a}}$, Ursula da Silveira Matte ${ }^{\mathrm{a}, \mathrm{b}}$ \\ ${ }^{a}$ Hospital de Clínicas de Porto Alegre, Porto Alegre, RS, Brasil \\ bepatamento de Genética, Universidade Federal do Rio Grande do Sul, Porto Alegre, RS, Brasil.
}

Histórico do Artigo
Recebido em:
10/01/2020
Aceito em:
20/05/2020
Palavras-chave:
Gestão de projetos;
recursos financeiros;
financiamento de
pesquisa; sistemas de
financiamento de
projetos

projetos

\begin{abstract}
RESUMO
A execução financeira e o cronograma de desembolso de recursos para projetos de pesquisa, geralmente, seguem padrões pré-estabelecidos de acordo com os editais de fomento, sem que haja uma análise detalhada dos fatores que determinam a sua execução. Para os gestores em pesquisa, este fato ocasiona a liberação de recursos em blocos, que são gastos em certo intervalo de tempo. O Hospital de Clínicas de Porto Alegre fomenta o desenvolvimento de pesquisas acadêmicas através de um Fundo de Incentivo à Pesquisa e Eventos. Sua utilização é condicionada à demanda das necessidades de insumos, serviços e atividades necessárias ao desenvolvimento dos projetos. O objetivo foi propor modelos matemáticos que auxiliassem no planejamento e acompanhamento financeiro de projetos de pesquisa. Foi realizada a análise descritiva dos recursos gastos entre 2005 e 2009, onde o modelo obtido, neste intervalo, foi testado nos projetos do período de 2011 a 2015. Os grupos tiveram comportamentos muito semelhantes, diferindo pouco nos tempos médios encontrados, entretanto, agrupamentos foram estabelecidos em virtude da similaridade dos resultados de suas análises. Os dados foram analisados de acordo com os tipos de projetos e demonstraram o percentual de recursos gastos a cada ano de execução, permitindo assim, estabelecer modelos de projeção para liberação gradual dos recursos como subsídio aos gestores de recursos financeiros na elaboração de projeções orçamentárias e cronogramas de desembolso financeiro para projetos de pesquisa, de acordo com os períodos de execução.
\end{abstract}

Propose of mathematical models that describes financial execution time of research projects supported by FIPE/HCPA

\section{ABSTRACT}

The financial execution and the disbursement schedule of resources for research projects generally follow pre-established standards in accordance with the development bids, without a detailed analysis of the factors that determine their execution. For research managers this fact determines the release of resources in blocks, which are spent in a certain time interval. In the Hospital de Clínicas de Porto Alegre case which fosters the development of academic research through a Research and Events Incentive Fund. Its use is conditioned by the demand for the inputs, services and activities necessary for the development of projects. The objective was to propose mathematical models to assist the planning and financial monitoring of research projects. A descriptive analysis of resources spent between 2005 and 2009 was performed, where the model obtained, in this interval, was tested on research projects developed from 2011 to 2015. The groups had very similar behaviors, differing slightly in the average times found, however groupings were established due to the similarity of the results of their analysis. Data were analyzed according to the projects types and showed the percentage of spent resources each year of execution, allowing the establishment of projection models for gradual resources release as a subsidy to the financial managers in the preparation of budget projection and financial disbursement schedules for research projects, according to the execution periods.

\section{Introdução}

O Hospital de Clínicas de Porto Alegre (HCPA) é uma instituição pública e universitária, integrante da rede de hospitais universitários do Ministério da Educação (MEC) e vinculada academicamente à Universidade Federal do Rio Grande do Sul (UFRGS). Atuando desde 1971, é um dos principais esteios da assistência pública à

\footnotetext{
* Autor correspondente: ckbral@gmail.com (Cabral C.F.)
} 
saúde da população gaúcha, oferecendo atendimento de excelência e alta complexidade em amplo rol de especialidades.

Todas as atividades são permeadas por um forte senso de responsabilidade social, promoção da cidadania e preservação ambiental. O HCPA coloca toda a sua estrutura à disposição para o desenvolvimento de atividades de ensino de graduação e pósgraduação, assim como para o desenvolvimento de pesquisas biomédicas, clínicas, experimentais e epidemiológicas, contribuindo fortemente para a disseminação de novos conhecimentos nestas áreas.

O Grupo de Pesquisa e Pós-Graduação (GPPG), criado em 1989, é o órgão responsável pela definição e implementação das políticas de pesquisa no Hospital de Clínicas. O GPPG gerencia a distribuição dos recursos do Fundo de Incentivo à Pesquisa e Eventos (FIPE), oriundo de uma porcentagem fixada em 0,8\% do faturamento anual do HCPA, utilizado para fomentar o desenvolvimento de pesquisas acadêmicas, no intuito de viabilizar a execução parcial ou total no âmbito da instituição. O FIPE possui caráter não competitivo, onde segundo suas normas, cada projeto é avaliado e categorizado, podendo solicitar auxílio financeiro, até certo limite, que poderá ser utilizado para aquisição de itens de custeio ou de capital, bem como auxiliar nas publicações e revisões de artigos científicos.

Projetos de pesquisa são plurianuais, ou seja, possuem cronogramas relativamente variáveis e muitas vezes extensos, podendo levar de dois a dez anos ou mais, dependendo do tipo de estudo que esteja sendo desenvolvido. Essa demanda acarreta a necessidade de aquisição de insumos, que poderão ocorrer em diversos momentos de seu cronograma, portanto, essa pesquisa teve a idéia de analisar o comportamento das despesas dos projetos de pesquisa, confrontando-as com seu cronograma físico.

Desde 2015, quando foi implantada a nova orçamentação anual do HCPA, o Serviço de Gestão em Pesquisa, vinculado ao GPPG, vem realizando um trabalho ativo na análise de projetos sem qualquer movimentação há mais de seis meses, que é o prazo exigido pelo Conselho Nacional de Saúde e pelas boas práticas em pesquisa, para entrega de relatórios parciais de acompanhamento. Essa análise terminou por encerrar diversos projetos por prazo e realizou o recolhimento ou devolução do saldo dos recursos remanescentes.

Em razão desta orçamentação, dos prazos dos projetos e dos recolhimentos que vinham acontecendo, surgiu a idéia de analisar o comportamento das despesas dos projetos de pesquisa, confrontando-as com seu cronograma físico. Essa análise visou demonstrar as ocorrências das despesas nos projetos e em que momentos elas ocorriam durante a sua execução.

A administração financeira é uma das tradicionais áreas funcionais da gestão, podendo ser encontrada em qualquer organização, tendo como premissas as análises, decisões e atuações relacionadas com os objetivos financeiros que são necessários às atividades das organizações. A função financeira integra todas as tarefas ligadas à obtenção, utilização e controle de recursos financeiros, de maneira que possa gerar estabilidade das operações, rentabilidade e otimização dos recursos nela aplicados. O campo de finanças é dinâmico e amplo, afetando diretamente a vida das pessoas e organizações. Gitman (1) faz uma definição do termo finanças como a arte e ciência de administrar o dinheiro, pois praticamente todas as pessoas físicas e jurídicas obtêm receitas ou levantam fundos, gastam ou investem dinheiro e, neste sentido, a administração de finanças diz repeito ao processo, às instituições, mercados e instrumentos envolvidos na transferência de dinheiro entre pessoas, empresas e órgãos governamentais.

As áreas de finanças podem ser divididas, segundo Gitman (1), em dois grandes blocos, de acordo com as oportunidades de carreira que o setor oferece: Serviços 
Financeiros e Administração Financeira. Serviços Financeiros é a área das finanças voltada à concepção e oferta de assessoria e a entrega de produtos financeiros às pessoas físicas, empresas e órgãos governamentais. Administração Financeira diz respeito às atribuições dos administradores financeiros nas empresas. Eles são responsáveis pela gestão dos negócios financeiros das organizações de todos os tipos, financeiras ou não, privadas ou públicas, grandes ou pequenas, com ou sem fins lucrativos.

Os administradores financeiros desempenham uma variedade de tarefas, tais como: elaboração de orçamentos, previsões financeiras, administração do caixa, administração do crédito, análise de investimentos e captação de fundos. Gropelli (2) afirmam que, para ter sucesso, os administradores financeiros têm de estar envolvidos com as alterações que ocorrem constantemente no campo das finanças, ou seja, serem responsáveis pelo conhecimento e respostas aos fatores de mudanças em todos os ambientes, sejam eles privados, públicos ou financeiros.

O processo orçamentário, como reforça Mendes (3), é dinâmico, mas não autossuficiente, porque a elaboração da proposta, que é a primeira etapa do ciclo orçamentário, renova-se anualmente e é resultante das definições da programação de médio prazo que, por sua vez, detalha o plano de longo prazo para integrá-lo ao processo de planejamento.

O ciclo orçamentário corresponde ao período de tempo em que se processam as atividades típicas do orçamento público, desde sua concepção até a apreciação final, conforme descreve MendesS (3). É um processo contínuo, dinâmico e flexível, por meio do qual se elabora, planeja, aprova, executa, controla e avalia a programação de dispêndios do setor público nos aspectos físico e financeiro. Já o exercício financeiro coincide com o ano civil, ou seja, inicia-se em $1^{\circ}$ de janeiro e se encerra em 31 de dezembro de cada ano, conforme dispõe o art.34 da Lei 4.320/1964 (4). Portanto, o ciclo orçamentário não deve ser confundido com exercício financeiro, envolvendo um período muito maior, iniciando com o processo de elaboração, passando pela discussão, execução e encerramento com o controle.

Nesse ponto, vale ressaltar que a Administração Financeira é uma atividade orientada por objetivos, onde as ações do administrador são relativas à análise e planejamento financeiro. Um dos objetivos da gestão financeira em projetos de pesquisa é assegurar uma estrutura financeira equilibrada, que não coloque em risco, no curto prazo, o desenvolvimento do projeto, garantindo-lhe uma estabilidade das atividades previstas no seu plano de trabalho.

Segundo Noronha (5), as avaliações realizadas em ambiente de pesquisa e desenvolvimento mostraram, nos últimos anos, que as perspectivas para realizar pesquisas têm melhorado consideravelmente, o que até certo ponto surpreende, pois um dos problemas frequentemente apontados no cenário científico nacional é o pequeno investimento e, por consequência, pouco desenvolvimento desta área no país.

$\mathrm{Na}$ área de pesquisa, a administração financeira atua na liberação e gestão de recursos, fazendo mais de acordo com as circunstâncias externas (disponibilidade de recursos) do que com as necessidades dos projetos (cronograma físico-financeiro). Notícias de atraso na liberação de recursos são frequentes, e o descompasso entre o ciclo orçamentário e o exercício fiscal é quase sempre uma realidade dos projetos. Por isso, em um cenário no qual a liberação de recursos é contingenciada anualmente e os projetos possuem execução plurianual, faz-se necessária uma adequação dos recursos à necessidade de desembolso.

Entende-se como cronograma físico de um projeto de pesquisa, a diferença entre a última despesa e a data da aprovação, ao passo que o cronograma financeiro pode ser definido como a diferença entre débitos durante determinados períodos. Para a análise 
do cronograma físico e financeiro dos projetos, foram consideradas as datas de aprovação, da primeira e da última despesa.

Mais especificamente no HCPA, os recursos solicitados pelos projetos de pesquisa são integralmente disponibilizados após a aprovação ética e metodológica pelo Comitê de Ética em Pesquisa (CEP), Comitê de Ética para Uso de Animais (CEUA) e pela Comissão Científica do HCPA, bem como da avaliação logística e financeira. A sua utilização pelo pesquisador está associada à demanda das necessidades de insumos, serviços e atividades necessárias ao desenvolvimento dos projetos, onde todos os processos de aquisição de materiais são realizados pelo próprio HCPA.

Diante da retração nos investimentos e cortes orçamentários realizados pelo Governo Federal, o HCPA, visando à perpetuação no incentivo ao desenvolvimento, reformulou em meados de 2015 sua orçamentação, adaptando-a a nova realidade nacional. As atividades de pesquisa e as despesas destinadas a aquisições externas receberam uma maior atenção, bem como controles mais eficientes. Dessa forma, o montante de recursos disponíveis anualmente para aplicação em pesquisa passou a ser determinado a partir do faturamento do ano anterior. Entretanto, a previsão de gasto seguiu sendo realizada a partir da demanda da comunidade de pesquisadores.

Em virtude do cenário atual da instituição, com foco na otimização de custos e recursos dos projetos e da constatação da necessidade do aumento no controle financeiro, é de extrema importância avaliar a criação de novos parâmetros sustentados por modelos matemáticos, que possam estabelecer a liberação de recursos de forma gradual e que estejam associados ao cronograma de desenvolvimento dos projetos.

Esta análise visa beneficiar o gerenciamento financeiro dos projetos, bem como uma eficiente gestão dos recursos aplicados e a possibilidade de fomentar uma quantidade maior de projetos a cada ano, não havendo a necessidade de comprometimento de todo o recurso disponível para investimento no ato da aprovação.

\section{Materiais e Métodos}

O projeto de pesquisa originário deste artigo foi aprovado em seus aspectos éticos, metodológicos e financeiros sob n ${ }^{\circ}$ 2016-0642 em 03/04/2017 pelo Comitê de Ética em Pesquisa (CEP) do HCPA para ser realizado na instituição. Os dados foram levantados e constituídos por todos os projetos de pesquisa que foram aprovados pelo CEP ou CEUA do HCPA no período de 2005 a 2015 (com exceção do ano de 2010), que receberam recursos do FIPE e que estavam com status de ENCERRADO ou ENCERRADO PRAZO no momento da coleta dos dados. O ano de 2010 foi excluído, pois neste ano, foi utilizado um sistema de distribuição de recursos diferente dos demais, sob a forma de conta-pesquisador e não por projeto, com agrupamento dos respectivos créditos. Essa sistemática não funcionou adequadamente, pois os recursos acabaram se misturando, gerando problemas na gestão de alguns projetos dentro da mesma conta. A partir de 2011, retornou-se ao modelo de disponibilização do recurso por projeto.

A coleta de dados foi realizada a partir de informações do banco de dados do GPPG, contendo informações referentes aos recursos recebidos e gastos pelo FIPE. Os dados foram exportados para o software Excel, a fim de auxiliar o manuseio e a tabulação das variáveis de interesse dos registros, sendo Tipos de Projetos (Desenvolvimento, Pesquisa em Animais, Pesquisa em Base de Dados, Pesquisa em Seres Humanos e Pesquisa de Material Biológico), Cronograma previsto e realizado e Cronograma de execução financeira.

$\mathrm{Na}$ formatação do banco de dados original, foram excluídos os nomes dos Pesquisadores Responsáveis, bem como qualquer tipo de informação quanto à 
identificação do projeto, permanecendo somente números sequenciais relativos aos anos dos mesmos. Em seguida, foram retirados os projetos do tipo patrocinado e uso compassivo, bem como os que apresentavam status de cancelado, arquivado e retirado, sendo respeitado o intervalo de tempo descrito anteriormente.

Quanto aos registros, foram excluídas todas as rubricas do tipo tradução, publicação e taxa de inscrição em congresso, uma vez que estas rubricas são consideradas como um apoio extra que os projetos podem solicitar após sua conclusão. Na sequência, foram removidos todos os dados em branco, com indicação de cancelado ou sem qualquer identificação, que não puderam ser mensurados.

Foram consideradas somente as receitas recebidas do FIPE. As complementações de verbas e créditos oriundos de fomentos externos, como Fapergs, Fundação Médica FMRS, CNPq ou outras, foram desconsideradas das análises.

Os projetos foram avaliados e, por possuírem características semelhantes, foram divididos em dois grupos, sendo o Grupo A formado pelos projetos dos anos de 2005 à 2009, utilizado para modelagem da fórmula de desembolso a partir da análise das despesas, tempos e cronogramas de execução; e o Grupo B, referente aos projetos dos anos de 2011 à 2015, para aplicação dos modelos.

Quanto ao percentual de distribuição dos projetos e recursos gastos para cada categoria, foram utilizadas as seguintes equações:

- Quantidade = Razão entre o número total de projetos da categoria e o total de projetos para todas as categorias;

- Receita = Razão entre a receita da categoria e o total das receitas;

- Despesa = Razão entre a despesa da categoria e o total das despesas;

- Uso do recurso (UR) = Quociente entre a despesa da categoria e a receita da categoria.

Para cálculo do tempo médio dos projetos, foram utilizadas as seguintes equações:

- Tempo Total = Diferença entre o último débito do projeto e a dada de aprovação;

- $\mathrm{TAD}\left(\right.$ Tempo da aprovação ao $1^{\circ}$ débito $)=$ Diferença entre o $1^{\circ}$ débito no projeto e a data de aprovação;

- CFIN (Cronograma Financeiro) = Diferença entre o último débito e o $1^{\circ}$ débito do projeto.

Para cálculo do comportamento das despesas por categorias de projetos, foi aplicada a equação abaixo:

- Despesa dos projetos nos períodos de execução = Razão entre a despesa da categoria no período (ano de débito) e o total da receita da categoria do ano correspondente.

A amostra total do Grupo A foi constituída por 1.394 projetos com registros válidos. Os projetos de pesquisa na categoria Outros representaram apenas $0,2 \%$ do total no respectivo período e mesmo com uma representatividade numérica de 11,4\%, os projetos de Base de Dados possuíam uma representatividade financeira muito baixa em relação ao total de verba recebida, de apenas $1,8 \%$, levando-os a serem desconsiderados das análises subsequentes. Já para os projetos de Desenvolvimento ocorreu o inverso, representando apenas 5,5\% do total de projetos, eles receberam quase $7 \%$ dos recursos. O subconjunto Pesquisa em Animais e Pesquisa em Seres Humanos correspondem por mais de $80 \%$ das despesas, sendo que a porcentagem de utilização dos recursos aportados para estes tipos de projetos foi de $90,5 \%$ e $75,2 \%$ respectivamente.

Portanto, após exclusão dos projetos de Pesquisa em Base de Dados e Outros, permaneceram no Grupo A apenas os projetos do tipo Pesquisa em Animais, 
Desenvolvimento, Material Biológico e Seres Humanos, totalizando assim uma amostra final de 1.233 projetos analisados. O tempo médio total dos cronogramas físicos dos projetos foi de 31 meses, com desvio padrão de 21 meses. Considerando-se o lapso temporal médio de 8 meses entre a aprovação, quando a verba é disponibilizada, e a realização do primeiro débito, tem-se como resultado o cronograma financeiro real médio dos projetos de 23 meses.

Para análise das despesas, foi definido um período de cinco anos, considerado pela soma do tempo total com seu desvio padrão, tendo como início da contagem exatamente o ano de aprovação do projeto com as despesas categorizadas, considerando-se o ano de registro do lançamento.

Considerando-se comportamentos semelhantes entre dois conjuntos das categorias, foram realizados agrupamentos em dois subgrupos definidos. Subgrupo I, formado por Pesquisa em Animais e Material Biológico e Subgrupo II, formado por Projetos de Desenvolvimento e Seres Humanos. Até o terceiro ano de execução, o Subgrupo I apropriou maior quantidade de despesas em relação do Subgrupo II, conforme nova análise realizada (Tabela 1). Os três primeiros períodos são os que concentraram o maior consumo dos recursos, com tendência de redução a partir deste, quando os projetos já estão em fase de conclusão dos trabalhos.

Tabela 1 - Comportamento e média das despesas dos Subgrupos I e II

\begin{tabular}{cccccccc}
\hline SUBGRUPO & $\begin{array}{c}\mathbf{2 0 0 5} \\
(\%)\end{array}$ & $\begin{array}{c}\mathbf{2 0 0 6} \\
(\mathbf{\%})\end{array}$ & $\begin{array}{c}\mathbf{2 0 0 7} \\
(\boldsymbol{\%})\end{array}$ & $\begin{array}{c}\mathbf{2 0 0 8} \\
(\boldsymbol{\%})\end{array}$ & $\begin{array}{c}\mathbf{2 0 0 9} \\
(\boldsymbol{\%})\end{array}$ & $\begin{array}{c}\text { Média } \\
(\boldsymbol{\%})\end{array}$ & Desv Pad \\
\hline (A+MB) & & & & & & & \\
$1^{\circ}$ Ano & 23,2 & 15,6 & 8,3 & 21,2 & 25,8 & 18,8 & 6,9 \\
$2^{\circ}$ Ano & 42,8 & 41,6 & 38,9 & 40,8 & 33,6 & 39,6 & 3,6 \\
$3^{\circ}$ Ano & 11,4 & 18,6 & 21,4 & 14,2 & 18,2 & 16,8 & 4,0 \\
$4^{\circ}$ Ano & 5,7 & 12,6 & 8,3 & 5,3 & 7,6 & 7,9 & 2,9 \\
$5^{\circ}$ Ano & 3,2 & 2,7 & 4,6 & 2,5 & 3,0 & 3,2 & 0,8 \\
\hline TOTAL & $\mathbf{8 6 , 2}$ & $\mathbf{9 1 , 0}$ & $\mathbf{8 1 , 5}$ & $\mathbf{8 4 , 0}$ & $\mathbf{8 8 , 3}$ & $\mathbf{8 6 , 2}$ & \\
\hline (D+SH) & & & & & & & \\
$1^{\circ}$ Ano & 10,2 & 7,5 & 4,8 & 11,1 & 10,6 & 8,8 & 2,6 \\
$2^{\text {o Ano }}$ & 29,3 & 26,4 & 32,8 & 26,4 & 31,9 & 29,4 & 3,0 \\
$3^{\circ}$ Ano & 17,3 & 13,7 & 20,9 & 16,8 & 18,8 & 17,5 & 2,6 \\
$4^{\circ}$ Ano & 9,8 & 10,7 & 7,3 & 9,1 & 7,4 & 8,9 & 1,5 \\
$5^{\text {o }}$ Ano & 5,2 & 3,4 & 5,6 & 7,0 & 2,0 & 4,6 & 1,9 \\
\hline TOTAL & $\mathbf{7 1 , 8}$ & $\mathbf{6 1 , 7}$ & $\mathbf{7 1 , 4}$ & $\mathbf{7 0 , 3}$ & $\mathbf{7 0 , 7}$ & $\mathbf{6 9 , 2}$ & \\
\hline
\end{tabular}

De posse desses dados, foi possível caracterizar duas curvas de tendência com as médias totais em percentuais por ano, bem como seus limites superior e inferior das despesas dos subgrupos em relação aos anos de execução (Figura 1). 


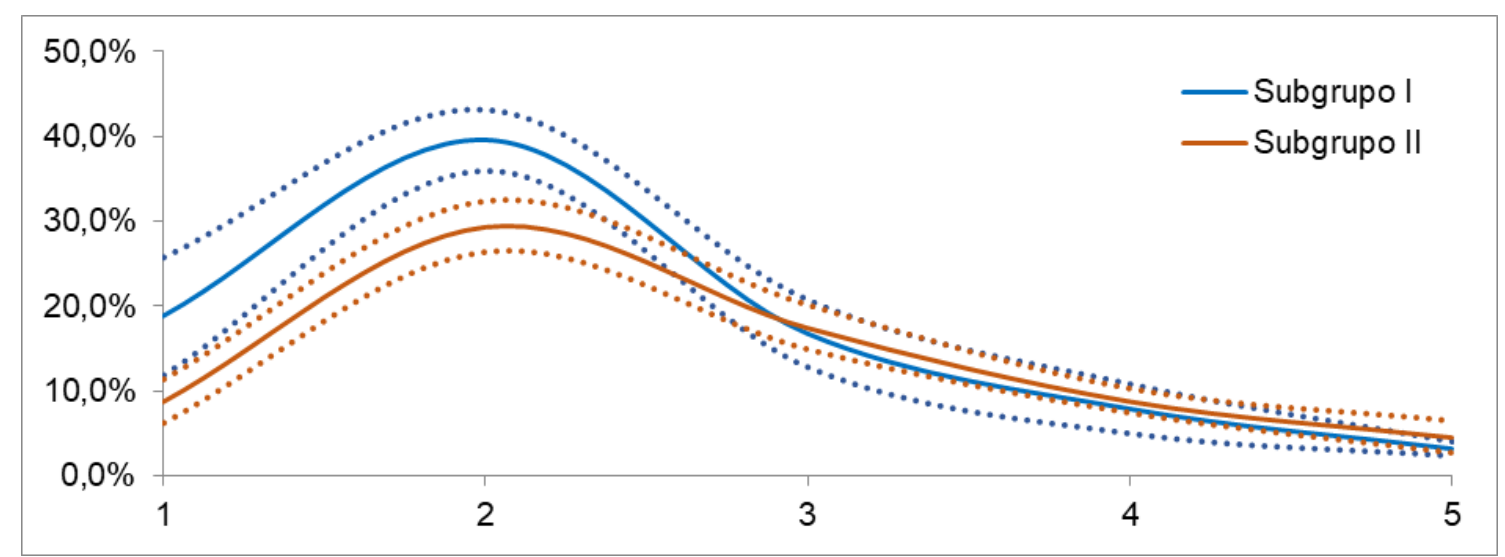

Figura 1 - Médias totais dos subgrupos I e II com limites inferior/superior (linhas tracejadas).

No entanto, para validar os dados obtidos no Grupo A, foi necessário calcular também os tempos médios do Grupo B, bem como a relação das despesas e receitas.

A diferença do Grupo B em relação ao Grupo A foi o surgimento de uma $5^{\text {a categoria, }}$ a de Pesquisa em Material Biológico de Animais, que fora segregada da categoria Pesquisa em Animais. O tamanho dos grupos mantiveram-se relativamente próximos, com 1.394 projetos no Grupo A e 1.572 projetos no Grupo B, assim como os tempos médios de execução de ambos também se mantiveram semelhantes, sendo 31 meses do Grupo A e 26 meses do Grupo B.

Analisando-se os dois grupos por tipos de projetos, verifica-se uma evolução no quantitativo das categorias, com exceção dos projetos de desenvolvimento que tiveram leve redução no Grupo B (Tabela 2). As pesquisas em material biológico praticamente duplicaram, devido à inclusão da nova categoria de Materiais Biológicos de Animais. As pesquisas com animais tiveram leve aumento e as de seres humanos mantiveram-se praticamente no mesmo nível.

Tabela 2 - Comparação dos Grupos A e B

\begin{tabular}{lcccccccc}
\hline & \multicolumn{4}{c}{ Grupo A } & \multicolumn{4}{c}{ Grupo B } \\
\cline { 2 - 9 } Categorias & Qtde & $\%$ & $\begin{array}{c}\text { Tempo } \\
(\text { meses) }\end{array}$ & $\begin{array}{c}\text { Desv. } \\
\text { Pad } \\
\text { (meses) }\end{array}$ & Qtde & $\%$ & $\begin{array}{c}\text { Tempo } \\
(\text { meses) }\end{array}$ & $\begin{array}{c}\text { Desv. } \\
\text { Pad } \\
\text { (meses) }\end{array}$ \\
\hline Desenvolvimento & 77 & $(5,5)$ & 32 & 20 & 50 & $(3,2)$ & 27 & 16 \\
Material Biológico & 124 & $(8,9)$ & 28 & 19 & 272 & $(17,3)$ & 25 & 14 \\
Pesquisa em Animais & 181 & $(13,0)$ & 35 & 22 & 274 & $(17,4)$ & 32 & 17 \\
Seres Humanos & 850 & $(61,0)$ & 28 & 21 & 976 & $(62,1)$ & 24 & 17 \\
\hline
\end{tabular}

Em continuidade à análise do Grupo B, foram calculados os percentuais das despesas em relação às receitas, com resultados das médias e seus desvios padrões. Como observado na primeira análise, também foi realizada a consideração de dois subgrupos sendo classificados como Subgrupo III, formado por Pesquisa em Animais + Material biológico + Material Biológico de Animais e Subgrupo IV, formado por Projetos de Desenvolvimento + Seres Humanos (Tabela 3). 
Tabela 3 - Comportamento das despesas dos subgrupos III e IV

\begin{tabular}{rccccccc}
\hline SUBGRUPO & $\begin{array}{c}2011 \\
(\%)\end{array}$ & $\begin{array}{c}2012 \\
(\%)\end{array}$ & $\begin{array}{c}2013 \\
(\%)\end{array}$ & $\begin{array}{c}2014 \\
(\%)\end{array}$ & $\begin{array}{c}2015 \\
(\%)\end{array}$ & $\begin{array}{c}\text { Média } \\
(\%)\end{array}$ & Desv Pad \\
\hline A+MB+MBA & & & & & & & \\
$1^{\mathbf{o}}$ Ano & 20,1 & 19,9 & 19,7 & 17,5 & 20,1 & 19,5 & 1,1 \\
$2^{\mathbf{o}}$ Ano & 38,2 & 39,2 & 35,2 & 34,4 & 39,7 & 37,3 & 2,4 \\
$3^{\mathbf{o}}$ Ano & 13,0 & 16,1 & 10,4 & 15,3 & 11,1 & 13,2 & 2,5 \\
$4^{\mathbf{o}}$ Ano & 7,4 & 4,0 & 7,2 & 6,2 & 1,7 & 5,3 & 2,4 \\
$5^{\mathbf{o}}$ Ano & 2,6 & 2,6 & 3,4 & 0,5 & 0,0 & 1,8 & 1,5 \\
\hline TOTAL & $\mathbf{8 1 , 2}$ & $\mathbf{8 1 , 9}$ & $\mathbf{7 6 , 0}$ & $\mathbf{7 3 , 8}$ & $\mathbf{7 2 , 6}$ & $\mathbf{7 7 , 1}$ & \\
\hline D+SH & & & & & & & \\
$1^{\mathbf{o}}$ Ano & 7,9 & 10,9 & 11,4 & 13,9 & 14,6 & 11,7 & 2,7 \\
$2^{\mathbf{o}}$ Ano & 20,5 & 25,3 & 21,9 & 20,8 & 21,3 & 22,1 & 1,9 \\
$3^{\mathbf{o}}$ Ano & 15,1 & 9,4 & 7,2 & 8,7 & 12,0 & 10,5 & 3,1 \\
$4^{\mathbf{o}}$ Ano & 5,5 & 5,4 & 5,8 & 4,8 & 0,6 & 4,4 & 2,2 \\
$5^{\mathbf{o}}$ Ano & 0,3 & 4,0 & 2,3 & 0,6 & 0,0 & 1,7 & 1,6 \\
\hline TOTAL & $\mathbf{4 9 , 2}$ & $\mathbf{5 5 , 1}$ & $\mathbf{4 8 , 6}$ & $\mathbf{4 8 , 9}$ & $\mathbf{4 8 , 5}$ & $\mathbf{5 0 , 4}$ & \\
\hline
\end{tabular}

Para efeito de comparação entre os subgrupos I - II e III - IV, foram inseridos os limites encontrados na análise dos subgrupos I e II. Considerando-se como limite superior o valor da média mais o desvio padrão, e inferior, a média menos o desvio padrão, observou-se a relação das despesas quase equivalente no Subgrupo III comparado ao Subgrupo I, onde a maioria das despesas ficaram dentro do intervalo de confiança do primeiro grupo.

Já na análise da relação do Subgrupo IV comparado ao Subgrupo II, ocorreu o inverso, houve pouca equivalência na comparação das despesas, onde as do Subgrupo IV ficaram abaixo do limite inferior do II, o que demonstra que houve redução nas despesas a partir do segundo ano. A resposta a esta redução se deve ao fato de que a partir de 2013, foram criados controles mais ativos nos projetos quanto ao tempo de validade e utilização dos recursos, onde foram feitos vários encerramentos por prazo para projetos que estavam sem movimentação há mais de seis meses. Com isso, muito dos saldos foram recolhidos ao fundo para viabilizar a fomentação de outros projetos em andamento.

Os anos de 2014 e 2015 não tiveram todos os valores das despesas contabilizados, pois o último ano de despesa de 2014, considerado na análise de cinco anos, é 2018, por isso os dados não estavam completos. Da mesma forma ocorreu com o ano de 2015, onde o quarto ano é 2018 e o quinto 2019.

A partir dos dados coletados e apresentados, analisou-se a distribuição das médias dos dois subgrupos, verificando-se que ambos possuem cronogramas de desembolso financeiro semelhantes, diferindo apenas em relação ao tempo que foram aplicados, conforme mostra a Figura 2. 


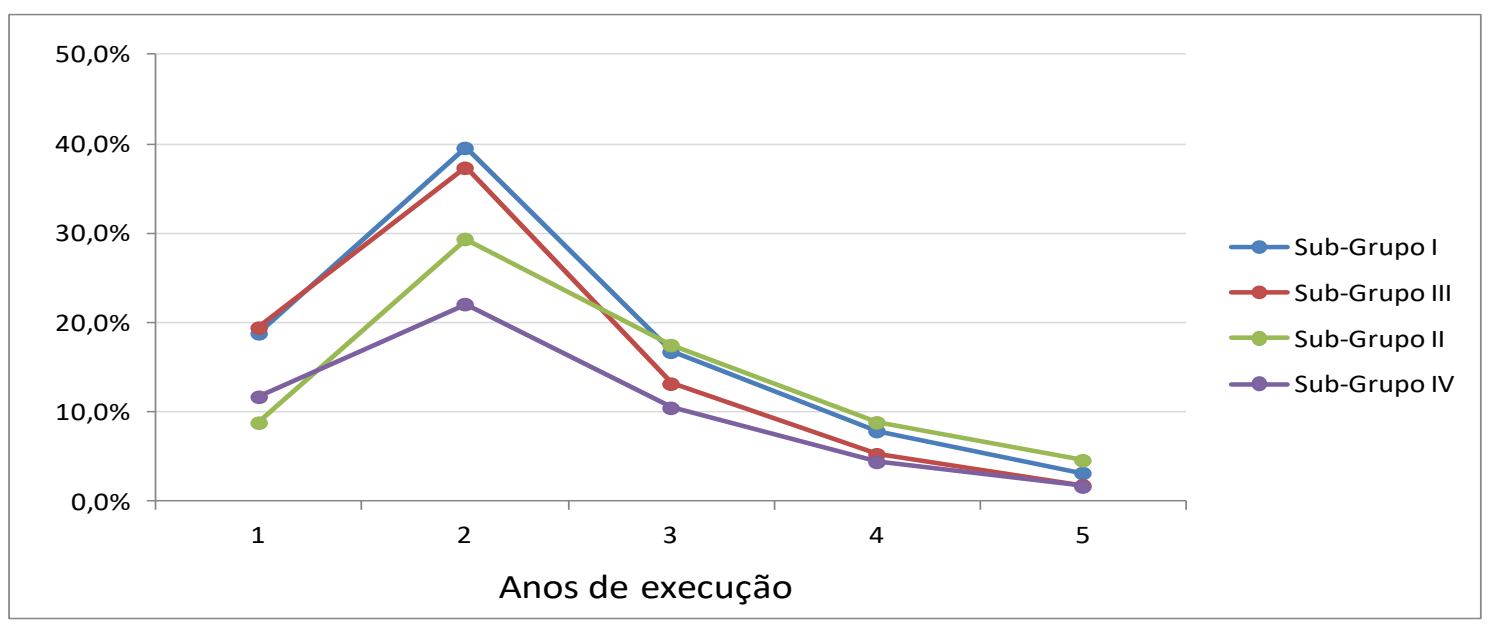

Figura 2 - Comparação das médias dos subgrupos I, II, III e IV.

\section{Resultados}

Desta forma, foi realizada a junção das curvas médias, definindo duas novas curvas médias estimadas. O modelo 1 foi definido para os subgrupos I e III, que referem-se à Pesquisa em Animais e Materiais Biológicos. O modelo 2 foi definido para os subgrupos II e IV, referindo-se aos Projetos de Desenvolvimento e Pesquisa em Seres Humanos. Devido ao comportamento semelhante das curvas tem-se então, os seguintes valores para as novas curvas médias únicas do período, conforme conjunto de subgrupo descrito na Tabela 4.

Tabela 4 - Curvas médias únicas - Modelos

\begin{tabular}{cccccc}
\hline Período & $1^{\mathbf{0}}$ ano & $2^{\mathbf{o}}$ ano & $3^{\mathbf{o}}$ ano & $4^{\mathbf{o}}$ ano & $5^{\mathbf{0}}$ ano \\
$(\%)$ & $(\%)$ & $(\%)$ & $(\%)$ & $(\%)$ \\
\hline Modelo 1 & 19,1 & 37,8 & 14,6 & 6,2 & 2,3 \\
Modelo 2 & 10,3 & 25,2 & 13,7 & 6,4 & 2,8 \\
\hline
\end{tabular}

Os modelos foram desenvolvidos para possibilitar as projeções orçamentárias dos projetos de acordo com os períodos em que estão sendo executados e estimar os montantes de recursos necessários para o desenvolvimento dos projetos em cada ano. A Tabela 5 demonstra que poderão ser utilizadas as médias como valores padrões. Entretanto, as projeções poderão utilizar ainda os desvios como limites superiores e inferiores dos valores a serem calculados em cada período adequando o modelo a uma proposta mais prática e funcional respeitando ainda a variabilidade dos projetos estudados.

Tabela 5 - Médias dos modelos com limites superior e inferior

\begin{tabular}{cccccccc}
\hline Modelo 1 & $\begin{array}{c}\text { MD - DP } \\
(\%)\end{array}$ & $\begin{array}{c}\text { Média } \\
(\boldsymbol{\%})\end{array}$ & $\begin{array}{c}\text { MD + DP } \\
(\%)\end{array}$ & Modelo 2 & $\begin{array}{c}\text { MD - DP } \\
(\%)\end{array}$ & $\begin{array}{c}\text { Média } \\
(\boldsymbol{\%})\end{array}$ & $\begin{array}{c}\text { MD + DP } \\
(\%)\end{array}$ \\
\hline $1^{\text {o }}$ Ano & 16,5 & 19,1 & 21,8 & $1^{\circ}$ Ano & 8,3 & 10,3 & 12,4 \\
$2^{\circ}$ Ano & 36,1 & 37,8 & 39,4 & $2^{\circ}$ Ano & 23,5 & 25,2 & 26,9 \\
$3^{\text {o Ano }}$ & 13,1 & 14,6 & 16,1 & $3^{\circ}$ Ano & 11,7 & 13,7 & 15,7 \\
$4^{\circ}$ Ano & 4,9 & 6,2 & 7,6 & $4^{\circ}$ Ano & 5,0 & 6,4 & 7,7 \\
$5^{\circ}$ Ano & 1,1 & 2,3 & 3,5 & $5^{\circ}$ Ano & 1,5 & 2,8 & 4,2 \\
\hline
\end{tabular}

Os modelos de cálculo foram definidos utilizando-se as médias dos modelos 1 e 2 bem 
como seus limites inferior e superior, utilizando-se as médias menos os desvios padrões e as médias mais os desvios padrões respectivamente conforme as equações abaixo:

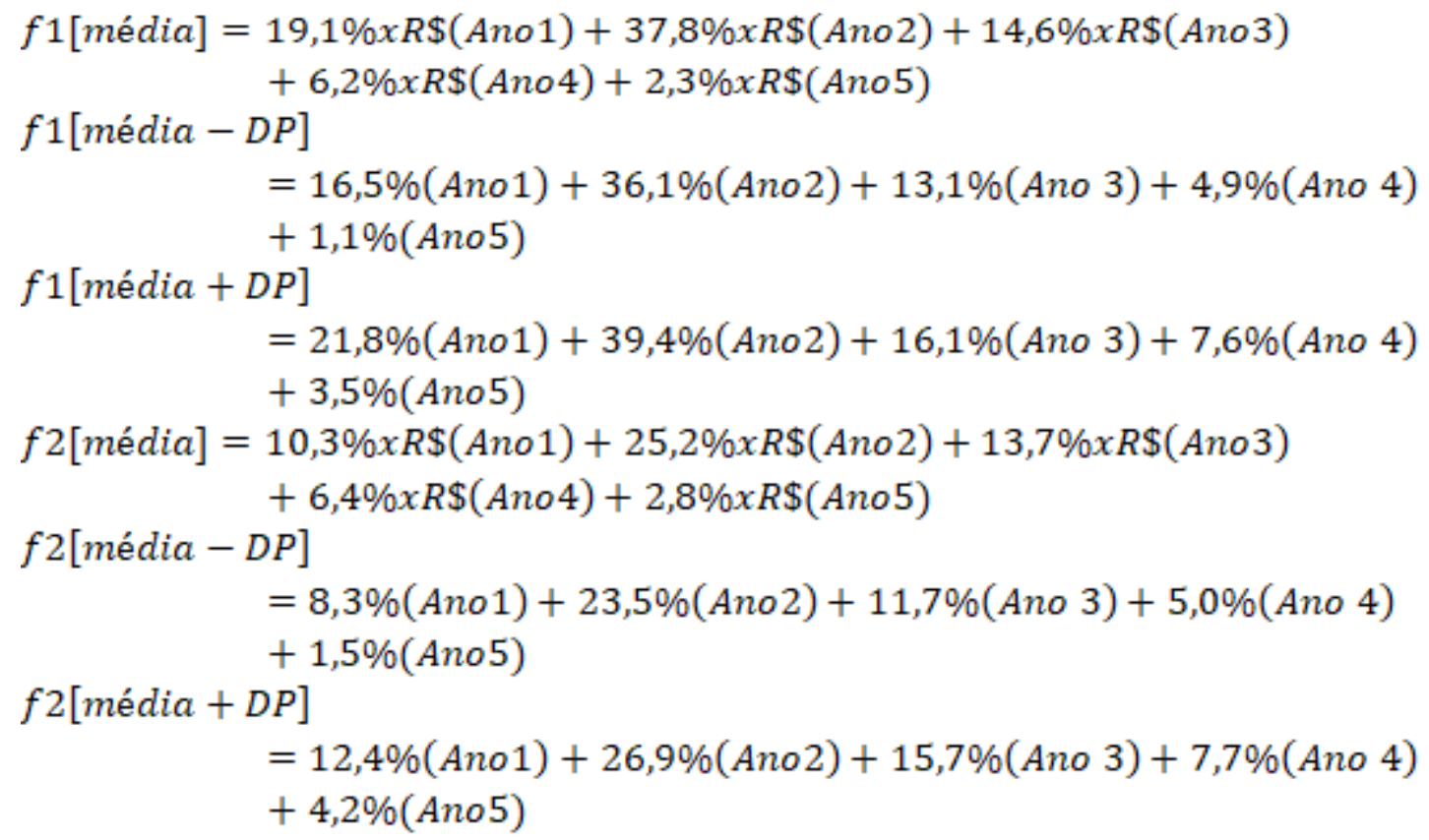

Para estimar a necessidade de orçamento de um dado ano, devem ser considerados os somatórios das porcentagens dos projetos que ainda estão em andamento de acordo com os períodos do momento. Esses valores passivos dos anos anteriores terão reflexo na orçamentação do ano projetado, pois a projeção de receita deverá ser pelo menos suficiente para suprir a demanda inicial e dar continuidade aos projetos em andamento.

O resultado, na verdade, não afirma que a receita projetada deverá ser fixada. Ela poderá ser aumentada ou reduzida, mas essas ações refletirão nas despesas e no valor passivo dos anos posteriores. Isso demonstra que, como os projetos são variáveis entre si e plurianuais, é extremamente aconselhável a correção constante das porcentagens dos modelos para um equilíbrio satisfatório das despesas e receitas aplicadas. Uma vez que as receitas são fixadas, é de suma importância um acurado controle das demandas dos projetos durante as execuções para uma gestão sustentável e equilibrada. O estabelecimento de um teto financeiro, baseado nas projeções, pode garantir um importante limitador de liberação de recursos no ano, onde uma vez atingido o limite nenhum recurso é disponibilizado.

Os modelos matemáticos propostos poderão servir como ferramenta complementar de análise e suporte, auxiliando os gestores de intituições públicas ou privadas no correto dimensionamento orçamentário dos seus recursos e aplicações aos projetos de pesquisa e talvez possam ser adaptados para aplicação em instituições que recebam ou realizem aporte de recursos, gerenciando os gastos e necessidades dos projetos de pesquisa. Uma vez que as análises foram desenvolvidas comparando-se diversos tipos de projeto e os resultados revelaram que seus comportamentos foram muito similares, seria perfeitamente viável sua utilização em qualquer modelo ou caracterização de projeto de pesquisa.

\section{Discussão}

Até o ano de 2014 não existia orçamentação definida por rubrica no HCPA. O direito ao uso do recurso federal era liberado sob a forma de contas e os diversos setores 
geravam suas demandas sem um controle pré-estabelecido, apenas realizando créditos e débitos entre essas contas. A partir do ano de 2015, a orçamentação por área foi implantada, onde o recurso federal passou a ser lançado em conta única e as atividades incluindo a de pesquisa passaram a receber valores definidos. Neste momento, houve a necessidade de se criar formas de controle das despesas, para que as demandas geradas pudessem ser atendidas dentro do exercício vigente.

Como o presente estudo foi realizado sob a perspectiva de uma realidade particular, os resultados levantados demonstraram que os dados foram tabulados e calculados em uma visão anual de orçamentação. Entretanto, revendo um dado importante da análise, que é o tempo da aprovação até o primeiro débito, verificou-se que, em média, os projetos levam sete meses para realizar seu primeiro dispêndio financeiro e, diante da visão de um planejamento com orçamentação mais estratégica e acurada, seria aconselhável realizar a projeção das despesas semestralmente e não anualmente.

Verificou-se, ainda, que o somatório das despesas de cada ano representou em média $74,5 \%$ das receitas e que 4,6\% correspondem à projeção do saldo restante dos projetos dos anos anteriores à amostra, ou seja, projetos mais antigos que ainda encontravam-se em atividade após cinco anos. O restante, cerca de 20,9\% dos recursos disponibilizados, não foi utilizado ou foi recolhido.

Conforme já foi dito anteriormente, houve uma diferença nos tempos de utilização dos recursos do Grupo 1 para o Grupo 2. O prazo mais curto no Grupo 2 é justificável, pois em 2015, com a implantação da orçamentação anual do HCPA, os projetos tiveram que antecipar suas programações de despesa. Assim, foi necessário realizar ajustes e readequações nas análises dos projetos, bem como criar controles mais rígidos, refletindo nos tempos de dispêndio, elevando as despesas no $1^{\circ}$ ano e, por consequência, antecipando as demais despesas nos períodos subsequentes.

\section{Conclusão e considerações finais}

Os resultados encontrados no presente estudo sugerem que, em razão de determinações, regulamentações e normativas institucionais e/ou governamentais, é de suma importância estar frequentemente atualizado com as regras de gerenciamento orçamentário que suportem decisões de médio e longo prazo, fornecendo elementos suficientes para uma gestão sustentável e duradoura do negócio, neste caso dos projetos de pesquisa.

Foram propostos modelos matemáticos que descrevessem os tempos de execução financeira dos projetos de pesquisa apoiados pelo FIPE/HCPA, mas que pelas suas características abrangentes pudessem ser aplicados a outras instituições de pesquisa.

Estes modelos foram gerados a partir da análise de dados de recursos financeiros dispendidos em projetos de pesquisa no período de 2005 a 2009, além de variáveis relacionadas com o tempo de execução financeira dos mesmos. Estes dados foram validados em projetos de pesquisa realizados no período de 2011 a 2015, sendo que os modelos matemáticos resultaram das análises conjuntas desses resultados.

Alguns achados deste estudo levantam novas questões acerca do gerenciamento dos projetos, bem como da utilização dos recursos. Estes poderão ser avaliados e estudados em perspectivas futuras. Alguns dos questionamentos surgidos durante a análise dos dados foram:

> Foram identificados lapsos temporais entre a disponibilização dos recursos e a ocorrência dos primeiros débitos. Quais fatores estão associados a este evento e como eles impactam no cronograma físico/financeiro dos projetos de pesquisa?

Se as despesas em média representam $74 \%$ das receitas, é interessante 
disponibilizar todo recurso solicitado na aprovação do projeto, se o valor a ser utilizado posteriormente será inferior?

\section{Referências}

1. Gitman LJ. Princípios de administração financeira. SãoPaulo 12. Ed., Pearson Prentice Hall, 2010.

2. Groppelli AA, Nikbakht E. Administração Financeira. São Paulo: Saraiva, 2010.

3. Mendes S. Administração Financeira e Orçamentária. 5.ed. São Paulo: Método, 2015

4. Art. 34 da Lei de Normas Gerais de Direito Financeiro - Lei 4320/64 - [acesso em 26 de fev 2020]. Disponível em http://www.planalto.gov.br/ccivil_03/leis/14320.htm

5. Noronha J, Silva TR, Szklo F, Barata RB. Análise do sistema de pesquisa em saúde do Brasil: o ambiente de pesquisa, Saúde e Sociedade 2009; 18(3): 424-436. 